\title{
Characterizing Breast Symptoms in Family Practice
}

\author{
Margaret M. Eberl, MD, MPH', \\ Robert L. Pbillips, Jr, MD, MSPH ${ }^{2}$ \\ Henk Lamberts, $M D, P b D^{3}$ \\ Inge Okkes, $P b D^{3}$ \\ Martin C. Maboney, MD, $\mathrm{PbD}^{1,4}$ \\ 'Department of Family Medicine, Univer- \\ sity at Buffalo, New York \\ ${ }^{2}$ The Robert Graham Center, \\ Washington, DC \\ ${ }^{3}$ The University of Amsterdam, \\ The Netherlands \\ ${ }^{4}$ Division of Cancer Prevention and Popula- \\ tion Sciences, Roswell Park Cancer Insti- \\ tute, Buffalo, New York
}

\begin{abstract}
PURPOSE The frequency and outcome of breast symptoms have not been well characterized in primary care settings. To enhance and inform physician practice, this study aims to establish the proportion of visits and resultant diagnoses by age by examining longitudinal data on breast-related reasons for encounter.
\end{abstract}

METHODS We used data from a prospective longitudinal sample of patients seeking care in Dutch family physician offices between 1985 and 2003 to provide routine family practice data on breast symptoms as the reason for encounter; all visits were coded using the International Classification of Primary Care. Data on breast symptom prevalence are based upon 84,285 active female patients and 367,834 total encounters.

RESULTS Overall breast symptoms were reported in about $3 \%$ of all visits by female patients (29.7 per 1,000 active female patients per year); breast pain and breast mass were the most common breast-related complaints. Breast symptom complaints were highest among women aged 25 to 44 years $(48$ of 1,000) and among women aged 65 years and older (33 per 1,000). Of the women complaining of breast symptoms, 81 (3.2\%) had breast cancer diagnosed. Breast mass had a markedly elevated positive likelihood ratio for breast cancer (15.04; 95\% confidence interval, 11.74-19.28).

CONCLUSIONS As expected, of patients with breast symptoms only a small subset was subsequently given a diagnosis of breast cancer (3.2\%); however, the presence of a breast mass was associated with an elevated likelihood of breast cancer. These data illustrate the use of systematic data collection and classification from primary care offices to extract information regarding disease symptoms and diagnoses.

Ann Fam Med 2008:6;528-533. DOI: 10.1370/afm.905.

\section{INTRODUCTION}

W hile the evaluation of breast symptoms is a hallmark of primary care practice, the frequency, evaluation, treatment, and outcomes of breast symptoms in female patients seeking care from primary care clinicians has not been well studied. A limited number of studies in the United Kingdom have examined visits to general practitioners for breast symptoms. ${ }^{1,2}$

The mean number of patients with breast complaints seen by general practitioners in the United Kingdom ranges between 2.1 and 3.5 visits per month. ${ }^{1,3}$ Even though breast cancer occurs infrequently among younger women, breast symptoms were relatively frequent, and anxiety regarding the possibility of malignancy is high. Three quarters of UK women who visited their general practitioner for a breast symptom were younger than 45 years. ${ }^{3}$ Also, two-thirds of visits to a breast clinic were completed by women younger than 35 years. ${ }^{1}$ Whereas most women were ultimately found to have a benign breast condition, delays of greater than 6 weeks between when the first symptom was noticed and medical evaluation ${ }^{4}$ and a low index of clinical suspicion may negatively impact survival. ${ }^{5}$ These studies suggest that a typical primary care clinician commonly encoun-
Margaret M. Eberl, MD, MPH

Roswell Park Cancer Institute

Elm and Carlton Streets

Buffalo, NY 14263

Margaret.Eberl@lifetimehealth.org 
ters women with breast complaints, most of whom are younger than 50 years.

This study uses a population-based sample of patients seeking care in Dutch family physician offices (1) to examine the frequency and types of breast complaints overall and by age-group, and (2) to determine which breast-related symptoms and concerns are most associated with a diagnosis of breast cancer.

\section{METHODS}

\section{General Description of the Data}

In the Dutch health care system every person is registered with a family physician. Because a referral from a family physician is needed for all specialty care, family physicians are involved in the great majority of all episodes of care among the Dutch population. Between 1985 and 2003, the Transition Project in the Netherlands comprehensively and prospectively coded office visits to family physicians based on the International Classification of Primary Care (ICPC). ${ }^{6-10}$ The term encounter is synonymous with an office visit in the United States. For the Transition Project, 58 Dutch family physicians routinely coded data on reasons for encounter, diagnoses, and interventions for all episodes of care they provided between 1985 and 2003. ${ }^{7}$ Given that each patient in the Netherlands must register with a family practice office, clinic-based participation is reflective of the broader population-based health care system. Only visits to physicians participating in the Dutch Transition project are contained in the study database; visits to nurse-practitioners and physician's assistants were not included.

In the Transition Project, a female patient could have 1 or more breast-related reasons for encounters. Treated as equally important and independent events each reason for encounter led to a final diagnosis that became the title for the episode. An episode of care is defined as "a health problem in an individual from the first encounter until the completion of the last encounter for it with a health care provider."7 Each family physician in the Transition Project participated for a minimum of 1 year. All episodes were coded according to the reason for the health care visit using the ICPC, the classification designated by the World Organization of Family Doctors as an ontology for the family medicine domain. ${ }^{7}$ The ICPC is a classification scheme recognized and accepted by the World Health Organization and the US National Library of Medicine that can be linked to the International Classification of Disease (ICD)-9 and ICD-10, but it more completely captures the reason for encounter and more effectively organizes conditions seen in primary care. ${ }^{10}$ Participating family physicians completed all coding for their patients; no cancer registry match was performed.
Using software developed for the project, a 17-year database was accrued representing 201,137 patients, 535,876 episodes of care, and 597,312 patient encounters $^{6-10}$; we based data in this report upon 84,285 active female patients who accounted for 336,752 episodes of care and 367,834 total encounters. In the Transition Project, a registered patient is an individual who is enrolled with a practice and receiving ongoing care. An active patient is a registered patient who received services from the family physician's practice at least once in the last year. Inactive patients are registered patients who have not received services during the observation period. ${ }^{9}$ All patients were registered from 1 to 10 years, with a mean registration of 5.6 years. Although it was possible for episodes of multiple breast complaint to be recorded for a single patient, each patient with a breast-related reason for encounter was counted only once at time of analysis; multiple occurrences were infrequently observed.

Breast symptoms include specific complaints, such as breast lump/mass, breast pain or tenderness, and nipple discharge; however, it is clear that women also come to physicians with fear of breast cancer and anxiety regarding their family history and risk of cancer. Fear of breast cancer is considered a unique reason for encounter in the Transition Project.

\section{Data Use and Analysis}

All data analysis conformed with the ICPC episode structure $^{7}$ and glossary definitions. ${ }^{7-10}$ We calculated the distribution of breast-related reasons for encounter for all women, as well as for the proportion of breastrelated reasons for encounter per 1,000 women across 4 age-groups (aged less than 25, 25 to 44, 45 to 64, and 65 and more years). A final diagnosis of benign (absence of neoplasm) vs malignant (including ductal carcinoma in situ, lobular carcinoma in situ, and histologic atypical) disease was assigned to each breastrelated reason for encounter, and similar comparisons were made across age-groups.

Clinicians often rely on the presence or absence of physical signs and symptoms, as well as such patient concerns as fear or perceived risk of breast cancer, to determine the likelihood, or probability, of breast cancer. Likelihood ratios can be useful in determining just how much concern for breast cancer should increase (or decrease) for a particular patient sign, symptom, or concern.

A positive likelihood ratio $(\mathrm{LR}+)$ is the ratio of sensitivity (true positive/[true positive + false negative]) to false positives, whereas the negative likelihood ratio (LR-) represents the ratio of false negatives to specificity (true negative/[true negative + false positive]). Clinically, a positive likelihood ratio corresponds to 
the concept of ruling-in disease, whereas the negative likelihood ratio corresponds with ruling out disease. Optimally, the positive likelihood ratio should be much larger than 1, with a $\mathrm{LR}+>3$ markedly increasing the likelihood of clinical disease; the negative likelihood ratio should approach 0 , with a LR $-<0.1$ markedly decreasing the likelihood of disease. Unlike predictive values, likelihood ratios do not change as the probability of disease changes; thus, they are particularly useful for determining risk of breast cancer by symptom regardless of age of the patient (http://www.poems. msu.edu/InfoMastery/Diagnosis/likelihood_ratios. htm). A true-positive result occurs when a woman reported a breast-related reason for encounter and the episode resulted in a breast cancer diagnosis, whereas a false-positive result occurs when women reported a breastrelated reason for encounter and the episode did not result in a breast cancer diagnosis. A truenegative result occurs when a women did not report a breastrelated reason for encounter and did not have the episode result in a breast cancer diagnosis, whereas a false-negative result occurs when a women did not report a breast-related reason for encounter although the episode resulted in a breast cancer diagnosis.

In this study we calculated proportions of breast symptoms and likelihood ratios for breast malignancy for each breast-related patient encounter overall, and by age-group (younger than 45 years and 45 years and older). As the analyses are meant to be exploratory and descriptive, we used univariate statistics.

\section{RESULTS}

In the Transition Project, the age distribution of encounters is skewed toward the older age-groups, likely reflecting greater use of health care services by older patients (Figure 1). The average breast-related episode (length of time from initial visit to end of the episode of care) lasted 10.2 days, (range, 8.6-11.9 days).

As displayed in Table 1, breast symptoms as the
Figure 1. Age distribution for episodes of care based on active female patients $(\mathrm{N}=84,285)$, Dutch Transition Project, 1985-2003.

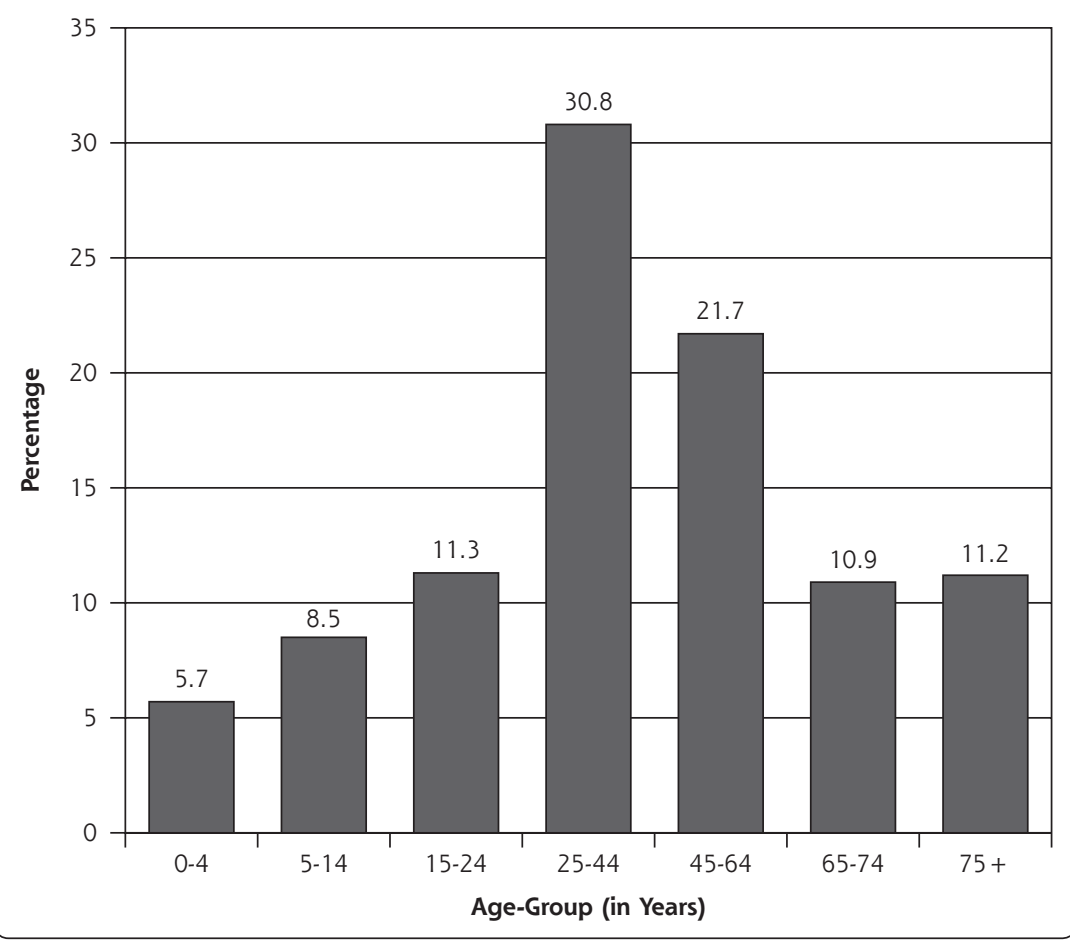

Table 1. Breast-Related Reasons for Encounter per 1,000 Visits per Year by Active Female Patients ( $N=84,285)$, by Age-Group, Dutch Transition Project, 1985-2003

\begin{tabular}{|c|c|c|c|c|c|}
\hline Reason for Encounter & $\begin{array}{c}<25 \text { Years } \\
\text { No. }(95 \% \mathrm{Cl})\end{array}$ & $\begin{array}{c}25-44 \text { Years } \\
\text { No. }(95 \% \mathrm{CI})\end{array}$ & $\begin{array}{c}45-64 \text { Years } \\
\text { No. }(95 \% \mathrm{Cl})\end{array}$ & $\begin{array}{c}65+\text { Years } \\
\text { No. }(95 \% \mathrm{Cl})\end{array}$ & Overall \\
\hline \multicolumn{6}{|l|}{ Breast symptoms } \\
\hline Breast lump/mass $(n=741)$ & $6.1( \pm 1.04)$ & $14.0( \pm 1.44)$ & $9.1( \pm .38)$ & $4.4( \pm 0.96)$ & $8.8( \pm 0.63)$ \\
\hline Breast pain $(n=1,191)$ & $7.4( \pm 1.15)$ & $23.6( \pm 1.87)$ & $16.5( \pm 1.86)$ & $6.3( \pm 1.14)$ & $14.1( \pm 0.80)$ \\
\hline Nipple complaint $(\mathrm{n}=210)$ & $1.4( \pm 0.49)$ & $3.7( \pm 0.73)$ & $3.0( \pm 0.80)$ & $1.7( \pm 0.59)$ & $2.5( \pm 0.34)$ \\
\hline Other breast complaint $(n=361)$ & $3.6( \pm 0.80)$ & $6.5( \pm 0.98)$ & $4.4( \pm 0.96)$ & $1.9( \pm 0.62)$ & $4.3( \pm 0.44)$ \\
\hline All breast symptoms $(n=2,503)$ & $18.4( \pm 1.82)$ & $47.7( \pm 2.66)$ & $33.0( \pm 2.63)$ & $14.3( \pm .72)$ & $29.7( \pm .16)$ \\
\hline \multicolumn{6}{|l|}{ Breast concerns } \\
\hline Fear of breast cancer $(n=303)$ & $0.8( \pm 0.38)$ & $4.2( \pm 0.77)$ & $6.0( \pm 1.09)$ & $3.7( \pm 0.85)$ & $3.6( \pm 0.39)$ \\
\hline
\end{tabular}


reason for encounter were noted in 2,503 of the 84,285 women $(3 \%)$. Breast pain $(n=1,191,48 \%$ of all breast complaints) and lump/mass ( $\mathrm{n}=741,29 \%$ of all breast complaints) were the most frequent complaints in the study population. The overall proportion of breast symptoms was 29.7 per 1,000 active female patients per year but did vary by age-group, with the highest proportions noted among women aged 25 to 44 years (47.7 per 1,000$)$ and women aged 45 to 64 years $(33.0$ per 1,000).

Overall, 81 of the 2,503 women (3.2\%) reporting

breast symptoms had breast cancer diagnosed. Most breast malignancies (78\%) occurred among women aged 45 years and older (rate among women aged 45 to 64 years, $0.33 \pm 0.13$ per 1,$000 ; 65$ years and older, $0.31 \pm 0.10$ per 1,000$)$, whereas women younger than 45 years had lower breast cancer rates (younger than 25 years, $0.02 \pm 0.03$ per 1,$000 ; 25$ to 44 years, 0.17 \pm 0.08 per 1,000$)$. As displayed in Figure 2, among the reported breast symptoms, breast lump/mass accounted for the highest rate of breast cancer diagnoses (8.1 per $100)_{\text {; }}$ the rate of breast cancer with other breast symptoms was lower.

Positive likelihood ratios and

Figure 2. Proportion of final diagnosis of breast cancer per 100 breast-related reasons for encounter, Dutch Transition Project, 1985-2003, by symptom/complaint.

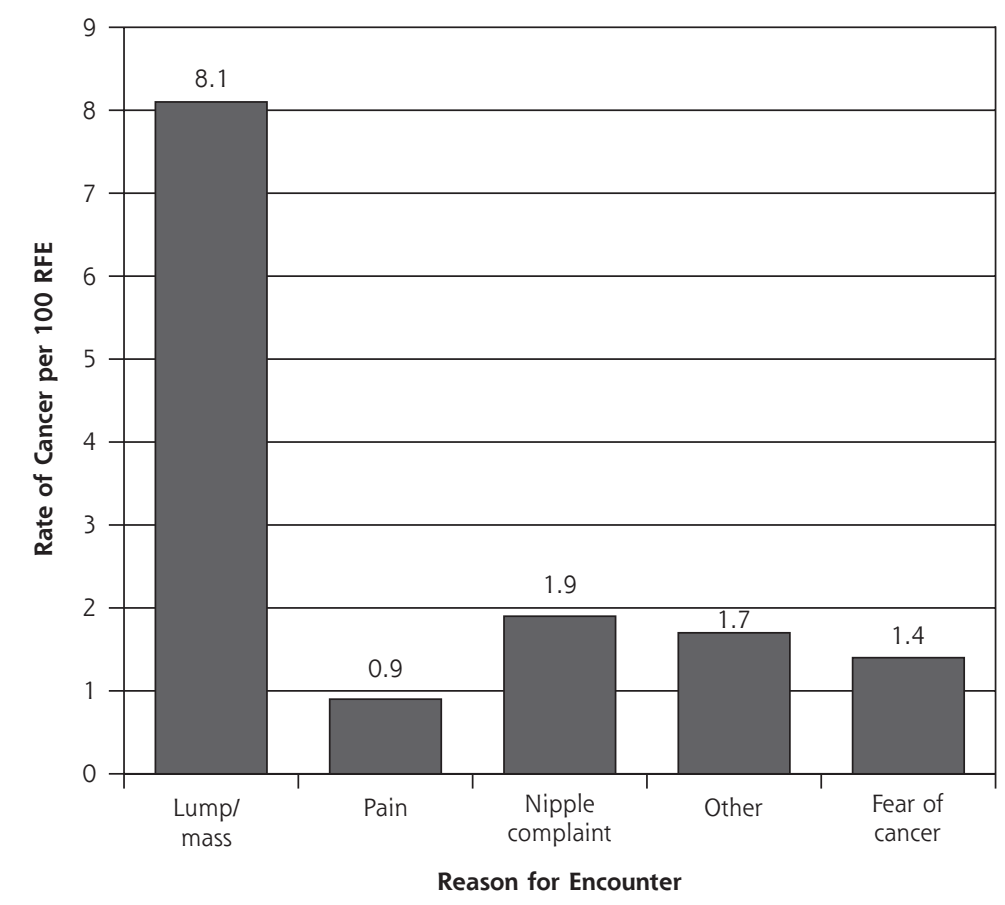

Other = other breast symptom; RFE = reason for encounter.

Table 2. Positive and Negative Likelihood Ratios for Breast-Related Reason for Encounter Reported by Visiting Female Patients, Based on Final Diagnosis of Breast Cancer, Dutch Transition Project, 1985-2003

\begin{tabular}{lcl}
\hline Reason for Encounter & LR+ (95\% Cl) & LR- (95\% CI) \\
\hline Any breast symptom & $5.41(4.42-6.63)$ & $0.86(0.83-0.90)$ \\
Breast lump/mass & $15.04(11.74-19.28)$ & $0.88(0.85-0.91)$ \\
Breast pain & $1.78(0.99-3.20)$ & $0.99(0.97-1.01)$ \\
Nipple complaint & $3.13(1.17-8.39)$ & $0.99(0.98-1.00)$ \\
Other breast complaint & $2.72(1.22-6.07)$ & $0.99(0.98-1.00)$ \\
Fear of breast cancer & $2.27(0.85-6.08)$ & $0.99(0.98-1.00)$ \\
\hline $\mathrm{Cl}=$ confidence interval; LR+ = positive likelihood ratio; LR- = negative likelihood ratio.
\end{tabular}
negative likelihood ratios, along with $95 \%$ confidence intervals, for breast-related reasons for encounter based upon a final diagnosis of breast cancer are shown in Table 2. Breast lump/ mass had a positive likelihood ratio for breast cancer of 15.04 (95\% CI, 11.74-19.28). In comparison the positive likelihood ratios among the other breastrelated reasons for encounter were considerably smaller and had overlapping confidence intervals, although the likelihood of having breast cancer diagnosed among women reporting a breast symptom of any type was elevated $(\mathrm{LR}+=5.41 ; 95 \%$ CI, 4.42-6.63). The negative likelihood ratio calculated for any breast symptom was significantly decreased $(\mathrm{LR}-=0.86 ; 95 \% \mathrm{CI}$, $0.83-0.90)$. The negative likelihood ratio calculated for breast lump/mass (LR- $=0.88 ; 95 \%$ CI, 0.85-0.91) was significantly distinct from the values for the other symptom categories. Age category (younger than 45 years and 45 years and older) did not modify these relationships.

Women reporting a fear of breast cancer, regardless of their age, did not have an increased likelihood of having breast cancer diagnosed $(\mathrm{LR}+=2.27$; 95\% CI, 0.85-6.08). If patients reported no breast lump or mass, their likelihood of having breast cancer was reduced $(\mathrm{LR}-=0.88)$. 


\section{DISCUSSION}

Data collection within community-based office settings within the United States can be both problematic and challenging. Researchers often rely on medical claims data and retrospective chart audits to piece together the care given to patients. At present, the frequency with which women in the United States visit their primary care physician with breast complaints is unknown, as are what is done for those complaints and what outcomes result from various interventions.

Results from this study among women seeking care in family physician offices in the Netherlands suggest that breast-related symptoms are not uncommon. In fact, nearly $2 \%$ of women younger than 25 years, $5 \%$ of women aged 25 to 44 years, $3 \%$ of women aged 45 to 64 years, and about $2 \%$ of women aged 65 years and older reported a breast-related symptom to their physician. Breast pain and breast mass/lump accounted for the most common breast complaints by patients, although breast-related symptoms varied by age-group.

It is interesting to note that the highest rate of breast-related complaints concerning breast symptoms occurred in an age range ( 25 to 44 years) that for the most part falls outside the age recommended for mammography screening. Although the incidence of breast cancers among women younger than 45 years is generally low, breast cancer does occur, and a thorough evaluation of all breast-related complaints is indicated.

Our analyses indicate that breast concerns and symptoms, especially a breast mass or lump, are associated with markedly elevated positive likelihood ratios for breast cancer, suggesting that clinicians should aggressively work up such complaints regardless of patient age. Likelihood ratios are useful in assessing the relationship between symptoms and disease. For example, the clinical finding of chest pain radiating to both arms has a positive likelihood ratio of 7.10 for myocardial infarction and negative likelihood ratio of 0.67 , whereas the finding of pleuritic chest pain has a positive likelihood ratio of 0.17 and a negative likelihood ratio of $1.20 .^{11}$ This study identified the highest positive likelihood ratio of breast cancer to be a breast lump/mass ( $\mathrm{LR}+=15.04)$. In comparison, the positive likelihood ratios for the other breast-related reasons for encounter (eg, breast pain, nipple complaint, other breast symptoms) were considerably less and generally comparable to each other. The positive likelihood ratio for patients who complained of fear of breast cancer was not significantly elevated. If patients do not report a breast lump or mass, their likelihood of having breast cancer is reduced, which may reassure both patient and physician ( $\mathrm{LR}-=0.88)$.

Although fear of developing breast cancer or having breast cancer identified on mammography has been reported extensively, we were unable to identify any published studies describing how fear of breast cancer influences the probability that breast cancer will be diagnosed. We also found that women reporting a fear of breast cancer, regardless of their age, did not have an increased likelihood of having breast cancer diagnosed. In comparison, the likelihood of having breast cancer diagnosed among women reporting a breast symptom of any type was elevated. Fear of breast cancer as a presenting complaint was highest among women aged 45 to 64 years, possibly because women in this group are exposed to screening mammography or their peers have developed breast cancer. Fear of breast cancer did not affect the positive or negative likelihood ratio.

Unique features of this analysis include use of data from a longitudinal study of family medicine officebased practices with systemic data collection and coding of visits using a structured classification and episode system. Results may have been influenced by the amount of time of patient participation (mean of 5.6 years), which could favor the occurrence of faster growing tumors, loss to follow-up, and potential for misclassification of patient-reported symptoms and reasons for encounter. Lactation status and problems with lactation were also not considered, which could alter interpretation of results. Even though it is not clear whether these results are comparable to those in the United States or other countries, the Dutch Transition Project is comprehensive and focused in family physician offices, suggesting broad generalizability.

We have found that symptoms of a breast mass or lump are associated with an elevated likelihood of breast cancer, suggesting that clinicians should aggressively work up such complaints regardless of patient age. On a broader scale, these analyses illustrate the use of systematic data collection and classification from primary care offices and community-based settings to extract information regarding disease symptoms and diagnoses. Such an approach requires use of a classification system that fits the care setting and the ability to aggregate visits to episodes of care both retrospectively and prospectively, as well as to track episodes of care. The second edition of ICPC $C^{7-10}$ offers a system for classifying and organizing primary care data and for extracting useful data about practices, people, and populations.

To read or post commentaries in response to this article, see it online at http://www.annfammed.org/cgi/content/full/6/6/528.

Keywords: Breast symptoms; breast diseases/diagnosis, primary care; data collection; referral and consultation/utilization; family practice

Submitted August 31, 2007; submitted, revised, May 30, 2008; accepted June 24, 2008. 
Funding support: This work was partially supported by the American Academy of Family Physicians Robert Graham Center through an internship awarded to Dr Eberl. In addition, Dr Eberl was also supported in part by a Physician Training Award in Preventive Medicine, from the American Cancer Society (Dr Mahoney, PI), which provided specialized training in cancer prevention and control.

\section{References}

1. Newton P, Hannay DR, Laver R. The presentation and management of female breast symptoms in general practice in Sheffield. Fam Pract. 1999;16(4):360-365.

2. Roberts MM, Elton RA, Robinson SE, French K. Consultations for breast disease in general practice and hospital referral patterns. Br J Surg. 1987;74(11):1020-1022.

3. Nichols S, Waters WE, Wheeler MJ. Management of female breast disease by Southampton general practitioners. BMJ. 1980;281(6253):1450-1453.

4. Max MH, Klamer TW. Breast cancer in 120 women under 35 years old. A 10-year community-wide survey. Am Surg. 1984;50(1):23-25

5. Burgess C, Hunter MS, Ramirez AJ. A qualitative study of delay among women reporting symptoms of breast cancer. Br J Gen Pract. 2001;51(473):967-971.
6. Kenter EG, Okkes IM, Oskam SK, Lamberts H. Tiredness in Dutch family practice. Data on patients complaining of and/or diagnosed with "tiredness". Fam Pract. 2003;20(4):434-440.

7. Lamberts H, Okkes I, eds. International Classification of Primary Care. Oxford: Oxford University Press; 1987.

8. Okkes I, Lamberts H. Classification and the domain of family prac tice. In: Jones R, ed. The Oxford Textbook of Primary Medical Care. Vol 1. Oxford: Oxford University Press; 2003:139-152.

9. Okkes I, Oskam SK, Van Boven K, Lamberts H. EFP. Episodes of care in Dutch Family Practice. Epidemiological data based on the routine use of the International Classification of Primary Care (ICPC) in the Transition Project of the Academic Medical Center/University of Amsterdam (1985-2003). In: Okkes IM, Oskam SK, Lamberts H, ed. ICPC in the Amsterdam Transition Project. Oxford: Oxford University Press; 2005.

10. Okkes IM, Becker HW, Bernstein RM, Lamberts H. The March 2002 update of the electronic version of ICPC-2. A step forward to the use of ICD-10 as a nomenclature and a terminology for ICPC-2. Fam Pract. 2002;19(5):543-546.

11. Cayley WE Jr. Diagnosing the cause of chest pain. Am Fam Physician 2005;72(10):2012-2021.

\section{CHANCE-OF-ADDRESS FORM FAMNILY MEDICINE}

Please complete this form and mail to the following address or fax to Annals Circulation at 913-906-6080:

Annals of Family Medicine, Circulation Department, 11400 Tomahawk Creek Pkwy, Leawood, KS 66211-2680

Check if member of sponsoring organization:

$\begin{array}{ll}\square \text { AAFP } & \square \text { ABFM } \square \text { STFM } \square \text { ADFM } \\ \square \text { AFMRD } \square \text { NAPCRG } \square \text { CFPC }\end{array}$

ID number from label on your journal cover

OLD Information (Please print.)

Name

Company (if applicable)

Address (Street plus Apt or Ste)

\begin{tabular}{ll}
\hline City & State \\
\hline Country & Postal Code (9-digit ZIP for US) \\
\hline Telephone & Fax \\
\hline E-Mail & \\
\hline
\end{tabular}

NEW Information (Please print.)

\begin{tabular}{ll}
\hline Name \\
\hline Company (if applicable) & \\
\hline Address (Street plus Apt or Ste) & \\
\hline City & Postal Code (9-digit ZIP for US) \\
\hline Country & Fax \\
\hline Telephone & \\
\hline E-Mail
\end{tabular}

